\title{
Managing paediatric obesity: a multidisciplinary intervention including peers in the therapeutic process
}

Helena Fonseca', António Labisa Palmeira ${ }^{2,3^{*}}$, Sandra Cristina Martins ${ }^{2}$, Liliana Falcato ${ }^{2}$ and António Quaresma ${ }^{2}$

\begin{abstract}
Background: Adolescent obesity epidemic is one of the major health priorities as it tracks into adult life. There is widespread need for new creative strategies and lifestyle programs. This study was designed to investigate the possible impact of including peers on the weight management program and assess the long-run adherence to behaviour change, with a potential positive impact on body mass index, body composition, and physical activity. Peer influence is major at this age and it is expected that adolescents will be better motivated and engaged in the behaviour changes when they are accompanied by their friends.
\end{abstract}

Methods/design: The study is a non-randomised, non-blinded controlled trial, including two groups: 1) Comparison group $(n=35)$, which will receive a 12 month standard treatment at the hospital setting plus a weekly interactive and physical activity session; 2) Experimental group ( $n=99)$, which will receive the standardized treatment at the hospital plus a weekly session together with a peer of their choice. The sample size calculations for the primary outcomes showed that we will have power to detect effect sizes of 0.25 . Measures include: a) Dual-energy $x$-ray absorptiometry (for body composition assessment); b) Anthropometric evaluations; c) Assessment of physical activity levels by accelerometers; d) Psychosocial mediators (motivation and peer support) assessed with a package of psychometric questionnaires; and e) Outcomes (quality of life and well-being).

Discussion: Adolescence is a crucial period for the development of a healthy lifestyle, especially among those who reach this age with an obesity condition. Obesity management programs directed to adolescents are often an adopted version of programs developed for children, most of them with a strong focus on the family, or an adopted version of adult programs, not recognizing the specificities of this age group. This study is designed taking into account the unique characteristics of this life-cycle stage, with the main objective of testing an innovative treatment for adolescent obesity.

Trial registration: This trial is registered in the clinicaltrials.gov with the number NCT02024061

Keywords: Adolescent, Obesity, Physical Activity, Weight Management, Peers

\section{Background}

Paediatric overweight and obesity have reached epidemic proportions in most industrialised countries [1]. In Portugal, a Southern European country with a traditional Mediterranean diet, the prevalence of overweight adolescents is among the highest in Europe. In a recent study [2], using a representative sample of Portuguese young people (22048 adolescents) aged between 10 and 18 years,

\footnotetext{
* Correspondence: antonio.palmeira@ulusofona.pt

${ }^{2}$ Faculdade de Educação Física e Desporto, Universidade Lusófona, Campo Grande 376, 1749-024 Lisboa, Portugal

${ }^{3}$ CIPER - Faculdade de Motricidade Humana, Universidade de Lisboa, Portugal Full list of author information is available at the end of the article
}

there was an estimated prevalence of overweight and obesity of $23.1 \%$ and $9.6 \%$, among girls and of $20.4 \%$ and $10.3 \%$ among boys, respectively. It was also seen that the prevalence of overweight and obesity decreases with age for boys and for girls from 13 to 18 .

It is of the utmost importance to work on prevention to deal with this epidemic [3,4]. However, efforts must also be made to treat those young people who are already overweight $[1,5]$. There are several facts to support this need, in particular because adolescent obesity: a) has a significant impact on physical and psychosocial health [6]; b) is an independent risk factor for adult obesity [7]; c) is an 
independent risk factor for mortality in adults, perhaps more powerful than adult obesity itself [8]; and d) is a major threat to the sustained increase of life expectancy [9].

The psychosocial consequences represent the most prevalent co-morbidities associated with obesity [10]. Obese young people have low self-esteem (SE) and a reduced quality of life (QoL), mainly associated with their perceptions of physical appearance, athletic skills and social functioning [6]. There seems to be a dose-response association between the Body Mass Index (BMI) and a worse health related QoL in such a way that severely obese people have significantly higher values than those seen in people with a less severe degree of obesity [11]. Moreover, obese individuals show higher levels of body dissatisfaction [12] and higher levels of depression [13]. Body Image (BI) has been consistently identified as a protection factor against the development of risky behaviour associated with obesity [14].

Obese adolescents with low levels of self-esteem have shown significantly higher levels of sadness, loneliness and anxiety and are more susceptible to engage in experimental/risky behaviours [9], such as smoking or drinking [15]. Fonseca and Matos [16] showed that overweight adolescents find it harder to make new friends when compared with their peers who are not overweight.

The questions of physical fitness associated with health are increasingly determinant in the way young people negotiate their daily lives and prepare for the future. In adolescents, a low cardiorespiratory fitness value is closely associated with an increased risk for developing cardiovascular diseases, regardless of country, age or gender [17]. To avoid the accumulation of risk factors for the development of cardiovascular diseases, the European Youth Heart Study [18] recommends that young people should perform more than one hour of moderate to vigorous physical activity (MVPA) per day. It has further been identified that higher amounts of MVPA hours are associated with a decrease in cardiometabolic risk factors [19]. However, an increase in physical activity (PA) alone does not solve the problem, as a decrease in sedentary behaviours (e.g. screen time) is crucial metabolic risk and adiposity control [20].

The health of individuals does not come only from their biology and/or individual actions but also from the biology and actions of those around them [21]. This issue is particularly relevant in adolescence as friends play an essential role in the developmental process, through the emotional support that is associated with social affection. Very often, peers are referred to as a barrier to regular PA and healthy diet [22]. More studies are needed to better understand these reciprocal influences, in order to be able to deal in a more effective way with the psychosocial factors negatively impacting the life of the obese adolescent [23]. Interventions that are intended to improve self-efficacy and social functioning in young people can bring specific benefits to obese adolescents [24]. However, and despite different authors e.g. [25], having suggested that an increase support from peers in contexts of PA implementation may constitute a viable way of promoting active lifestyles among young people, this area has still not been much studied.

Although the literature consistently points out the direction for solving the problem, it has generally not been possible to directly and effectively influence PA [26]. Interventions using mediators have shown effective results in changing behaviour in the short term and there is increasing evidence that this approach may have long-term effects [27]. The role of self-efficacy has been clearly pointed to as a mediator in the relationship between the intervention and PA [28]. Recently, Rhodes and Pfaeffli [29], in a wide-reaching review, suggested that changes in the structure of self-regulation might have a greater mediator effect on changing behaviour relative to PA.

Our program, named Tratamento da Obesidade Pediátrica (TOP), standing for Paediatric Obesity Treatment, has been implemented in 2004, and is the result of the cooperation between the Paediatric Obesity Clinic, Department of Paediatrics, at Hospital de Santa Maria (HSM) and the Faculty of Physical Education and Sport at Universidade Lusófona (UL) in Lisbon. This initiative gave rise to an innovative, yet sustained programme where several disciplines including PA specialists are simultaneously present in the Clinic, making it possible that adolescents receive integrated medical, nutritional and PA care on the same day. Respecting the most recent recommendations [30], we use behaviour modifying techniques aimed not only at the adolescents but also at their families and peers, using techniques based on the Self Determination Theory (SDT) and Motivational Interviewing (MI) [31] within a treatment protocol that has been presented at the Society for Adolescent Health and Medicine [32]. Based on our previous experience and on recent literature, it was theorised that to provide better care it would be necessary: a) more extensive and frequent contact with the treatment team and b) the inclusion of peers to assist in the weight control tasks. The literature shows that an adolescent's health behaviour is associated with that of their peers [23], through social contagion [33,34] mechanisms. The reasoning behind the design of this project is the belief that providing regular PA, interactive sessions (IS) [35] and specific moments of concentrated intervention - holiday camps [36], would offer the right context for both reaching a more extensive contact with the treatment team and allow for the inclusion of peers in the treatment. This intervention is grounded on the rationale presented and the health behaviour modification model, based on the Self-Determination Theory - SDT [37]. The team believes that this interaction between PA, positive psychological effects and reduction in BMI will lead to an increase in the perceived well-being of adolescents, which 
in turn will reinforce health behaviour, as has been seen with adults [38].

\section{Objective}

The main objective of this project is the development, implementation and assessment of an adolescent obesity treatment programme, which will use PA and interactive sessions to promote skills for achieving weight control in a context of increased contact between the adolescents, peers and the team.

As such, the following objectives were defined:

1. To contribute to an effective weight management of adolescents, through reducing the BMI z-score and\% Fat Mass (FM), increasing PA and reducing sedentary behaviour;

2. To analyse the effects of including peers and an increased exposure time of adolescents to PA and IS, on psychosocial health, eating habits, physical fitness and metabolic and inflammatory markers.

\section{Methods/design}

\section{Study design and setting}

The study is experimental and will be based on a NonRandomised, non-blinded Controlled Trial including two groups: a) A Comparison group, which will receive the standard treatment at the clinical setting, including medical assessment, dietary and PA counselling every 3 months, with access to a 12-month programme including weekly IS and PA sessions and holiday camps; b) An experimental group which, in addition to the standard treatment, will have access, together with a peer of their choice, to a 12-month programme including weekly IS and PA sessions and holiday camps. The adolescents will be allocated to the groups according to the existence or not of peers of their choice to escort them in the intervention.

The setting of the study will be an Exercise and Health University Study Centre and the Paediatric Obesity Outpatient Clinic at Hospital Santa Maria (HSM). All participants will be recruited in the Lisbon region, Portugal (Figure 1).

\section{Ethics approval and registration of the trial}

The Ethics Committee of Faculdade de Medicina de Lisboa, University of Lisbon, approved this study, with the number 092/2013. Written consent will be obtained from both the adolescents and their parents or legal care providers. The study is registered in clinicaltrials.gov with the number NCT02024061.

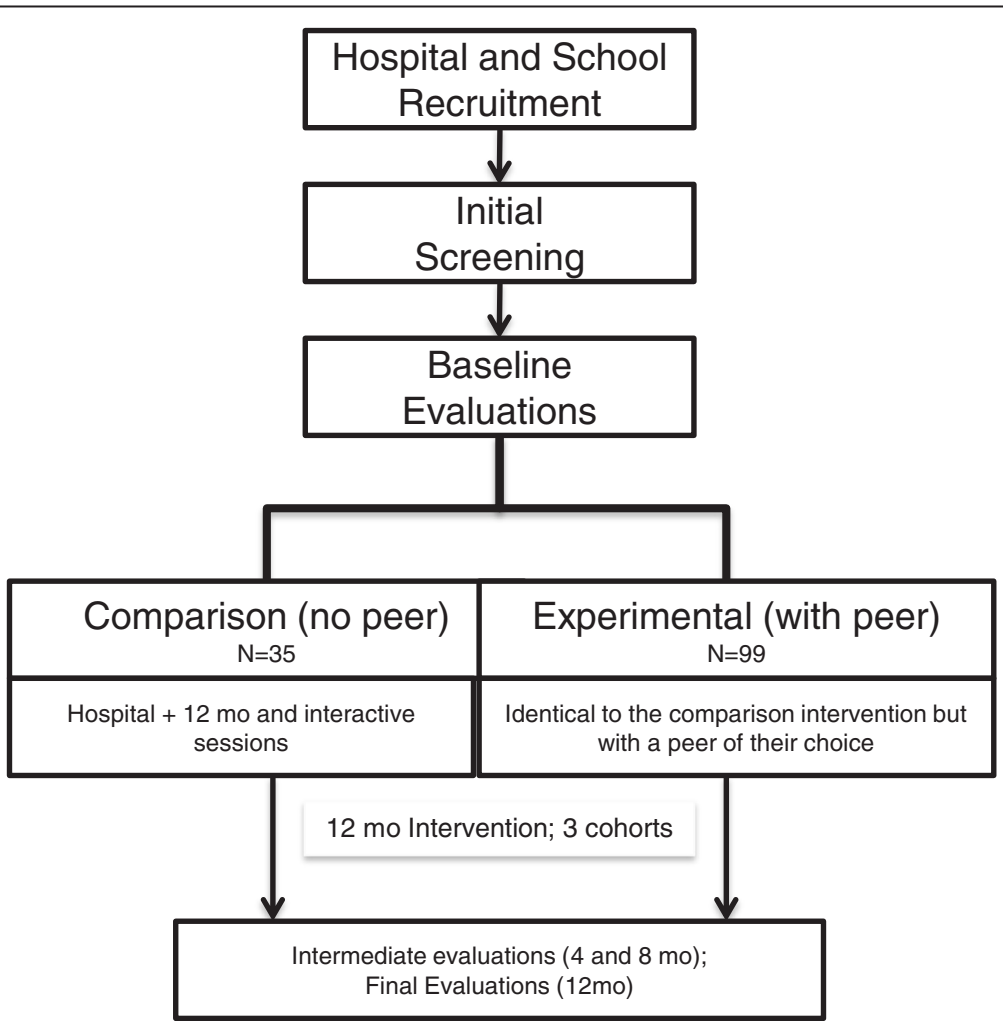

Figure 1 Study design. 


\section{Participants}

The participants will be randomly selected from two origins: the Paediatric Obesity Clinic at HSM and schools in the Lisbon region. Adolescents from the schools will be identified as obese by their Physical Education teacher based on their BMI percentile [39], and referred to the HSM Clinic for further assessment before being included in the study.

\section{Sample size calculations}

To calculate the sample size we focused on the primary outcomes, using two-tailed tests $(\mathrm{p}<0.05)$, for a power of 0.90 . For the projected sample (134), we estimate that the analyses will have a power to detect effect sizes of 0.25 . Specifically, we estimate that our groups should be made up of: 99 participants, divided into 3 cohorts of 33 participants - experimental group; and two cohorts of 12 participants and one of 13, in the comparison group. We are aware that a lengthy intervention may result in an attrition rate of about $25 \%$, so we are expecting a drop to 0.82 in the study' power, if this attrition is observed.

\section{Eligibility criteria}

Inclusion Criteria: Obese adolescents with a BMI greater than or equal to the $95^{\text {th }}$ percentile [39], aged between 14 and 17, with Caucasian origin, agreeing with the commitment.

Exclusion criteria: a) cognitive impairment; b) pregnancy; c) serious illnesses; d) other factors with contraindication for regular PA.

\section{Subject withdrawal}

The following will give rise to the withdrawal of participants:

- Attendance less than $75 \%$ of the IS or PA sessions;

- Acute illness implying non-compliance with the planned sessions;

To ensure that the participants comply with the assumptions, records will be kept of the attendance at the IS and PA sessions. Participants will not be substituted.

\section{Intervention}

The study comprises an experimental group and a standard treatment group. The intervention will be similar in both groups with the exception that in the experimental group every adolescent will be escorted by a peer of their choice at every moment of the intervention (IS, PA sessions and holiday camps). The multidisciplinary team is made up of physical activity specialists, nutritionists/dieticians, psychologists and paediatricians, all of them with previous training in adolescent obesity, resulting from their involvement in the Paediatric Obesity Clinic at HSM.

\section{Interactive sessions}

Both the comparison and experimental groups will meet the intervention team once a week. These meetings are conducted with both groups, with the intervention being identical in its contents, since the differential factor is the presence or absence of the peer of choice. The joined session will last for about 120 minutes, covering contents on PA/exercise, nutrition and behavioural change in a context of small activity groups (including peers), using an experiential learning methodology, which consists of increasing one's skills through transforming the experience [35].

The main objective is to bring the participants closer to independent decision making on their wish to make changes about their lifestyle and weight status (and how to do so), and subsequently help them to face the consequences of their choices, regardless of the results.

The participants are encouraged to discover situations in their daily lives that can be changed in order to increase the number of calories burnt by more than 2000 Kcal per week [39]. This can be achieved more formally (physical exercise in a guided context) or informally (PA). The University offered an exercise room that is available for daily use by the participants. Each participant will be given a pedometer to help monitor the number of steps taken each day. The use of pedometers has been associated with significant increases in PA and significant reductions in BMI [40].

The intervention is based on a group functioning rationale which, in accordance with the social contagion theory [33], may contribute to positively influence the different members of the group. Peer group influence is major at this age and it is expected that young people will be more active when they are accompanied by their peers and their friends [41]. Benefits arising from group work, in the context of obesity management, were obtained through improving social functioning, which was positively associated in dimensions related with self-concept [34]. This effect was also seen in a recent study [42], which was intended to assess a PA intervention based on the use of pedometers and provision of support material to peers. It has been shown that the best results were obtained in the group that received only peer support material and objectives to be reached with the use of the pedometers. Salvy and colleagues [41], in a study with 88 adolescents, showed that the presence of a friend increased the motivation to be physically active. The use of peer and/or family support material has been suggested as an effective mean of promoting PA in young people at risk of sedentary behaviours [43], both at the beginning of the maintenance phase [44], and as an ongoing source of support for improving psychosocial functioning [45].

The IS included a variety of challenging physical activities, support provision for definition of a structured training plan, adjustment of daily tasks according to an active 
lifestyle, reduction/modification of sedentary behaviour strategies (e.g. reduction of screen time), help in discovering the preferred type of activity overcoming some myths and barriers around exercise/PA, and support in ambivalent behaviour. Because PA is the main modifiable component associated with energy expenditure in the energy balance equation [39], various international organisations have looked at PA promotion as a crucial modifiable health behaviour [46].

In addition to encouraging $\mathrm{PA}$, it is equally important to reduce/modify sedentary behaviour $[39,47]$. Tremblay et al. [48], in a systematic literature review, showed that over 2 hours of television a day was associated with an unfavourable body composition, less physical aptitude, lower self-esteem values and more maladjusted social behaviour. According to the Canadian Sedentary Behaviour Guidelines for Children (5-11y) and Youth (12-17y) recently launched, it is recommended that for health reasons, children and adolescents should reduce daily sedentary time, by means of limiting screen time to a maximum of 2 hours a day, avoiding motorised transportation, along with the reduction of sitting time and time spent "inside the house" [49].

The IS also seek to provide self-regulation strategies for diet/nutrition behaviour improvement through providing information focused on increased awareness about nutritional facts; negotiating the modification of dietary patterns [50]; and using the food traffic light [51]. According to the recommendations of Spear et al. [39] and Davis et al. [52], there will be a focus on learning specific strategies/skills which include the importance of breakfast; increasing the number of meals during the day; avoiding hunger and unregulated consumption; reducing emotional (compulsive) and/or distracted eating; eating according to energy needs; consumption of food with a high satiety index; reduction in food consumption rich in animal fat; increase in the consumption of fruit, vegetables, cereals and other fibre rich foods; reduction in sugar consumption; limited consumption of drinks and fast food; lower portions size; and learning how to read and understand food labels.

With regard to cognitive-behavioural modification, the focus will be on the identification of problems and face the difficulties that arise during the programme. As there is nothing more central to behaviour than motivation, the whole interaction will be self-motivation and self-regulation centred, seeking to identify personal resistance and barriers, developing skills for prevention, identification and overcome [52]. Specific strategies [39] will include: the increase in self-efficacy through analysing and overcoming typical barriers such as lack of time, skill or accessibility; making planning more flexible; positively accepting failures, and/or that change is neither quick nor easy; building a system of incentives; and defining realistic, tangible objectives.

\section{Physical activity intervention}

The physical activity intervention will comprise a weekly exercise session, taking place on the same day of the interactive session, and the use of pedometers to promote the increment of PA during the rest of the week. To progressively reach the 60 minutes of MVPA, we will aim that adolescents take 10000 to 11700 steps every day by the end of the intervention [53], specifying individual plans depending on their initial physical activity stage.

The exercise sessions will comprise several types of activities, from group classes focusing on aerobic exercises, sports, walking or running periods, dance, to strength sessions. We intend to show an extended array of activities that can be then adopted by the participant. Each session is planned for 60 minutes providing moderate to vigorous intensities.

More specifically, the strength sessions are planned according to the initial assessment carried out according to the 10-RM test. The training load is estimated for $50 \%$ of theoretical 1-RM [54]. The training plan consists of a circuit with 8 exercises for strength training, alternating between the torso and lower limbs. There will be $2 / 3$ series of moderate intensity (30" activity alternated with a $30^{\prime \prime}$ break) or vigorous intensity (45" of activity alternated with a $15^{\prime \prime}$ break), thus respecting all of the recommendations [55]. Moderate to vigorous cardiovascular exercises, from 50 to $85 \%$ of the HR Reserve [54] will also be included, with a total volume of 10 to $30 \mathrm{mi}$ nutes, according to the choice of the participants. The intensity of each exercise will be monitored both through the use of a heart rate monitor and the use of the perceived exertion scale for young people (OMNIA-RES) [56].

\section{Discontinuation}

If participants miss more than $25 \%$ of the sessions, they will be removed from the analysis. The intervention will be discontinued if more than $50 \%$ of participants give up.

\section{Data collection}

The variables will be assessed according to Table 1 .

\section{Outcomes}

Taking into account the recommendations of Barlow [57] and following analysis of the results of two recent meta-analyses $[1,5]$, the following outcomes were defined (see Table 2).

\section{Data analysis}

We plan to use repeated measures analysis of variance to evaluate the impact of the intervention. Additionally, we plan to use structural equation models and/or multiple mediation analyses to assess the presence of predictors of the results of the intervention [58]. 
Table 1 Variables, measures and timing of the data collection

\begin{tabular}{lll}
\hline Parameters & Assessed through... & When \\
\hline IS attendance & Attendance sheets & IS \\
Frequency of exercise & Training plans and attendance records & IS and Exercise sessions \\
PA & $\begin{array}{l}\text { Pedometers (OMRON Walking Style II, HJ-113-E) PA records } \\
\text { (7-Day Physical Activity Recall) }\end{array}$ & IS/Holiday Camps \\
PA and Sedentary behaviour & Accelerometers (Actigraph GT3X) & \\
BMI & Weight (OMRON BF-500) SECA height stadiometer & $0,4,8,12,24,36$ months \\
\% Fat mass & Bioimpedance (OMRON BF-500) & \\
Body composition & Dual-energy X-ray absorptiometry, DEXA (QDR-1500; Hologic, Waltham, MA) & \\
Physical fitness & FITNESSGRAM test battery & \\
Caloric intake & Food records (4-day recall) & \\
Quality of Life & Impact of Weight on Quality of Life - Kids (IWQOL-kids) Kidscreen-27 & \\
Well-being & Rosenberg Self-Esteem Scale (RSES) Body Image Assessment Questionnaire & \\
Peers & (BIA) Body Shape Questionnaire (BSQ) & \\
Self-regulation variables & Perceptions of Parents Scales (POPS) - adapted to peers Self-Perception Profile & \\
& for Adolescents (SPPA) - Social Acceptance Scales and "Best Friends" & \\
& Treatment Self-Regulation Scale (TRS) Locus of Causality for Exercise (LCE) Weigh \\
\hline
\end{tabular}

Notes: IS - Interactive sessions; PA - Physical Activity.

The intention-to-treat principle (last observation carried forward) will be followed for handling the missing data.

\section{Discussion}

The aetiology of paediatric obesity is influenced by biological, physiological, environmental and contextual factors [59], with human behaviour being the aggregator factor not only in obesity but in health in general [60]. This intervention is mainly intended for a better understanding of how behaviour can be modified.

Adolescence is that time in life where the ability to learn increases and new habits are adopted [61]. This issue is one of the strongest aspects of the intervention, which intends to enhance the perspective of positive health both based on the increasing individual autonomy and on the peer group interaction as a key element for understanding and potentiating various positive kinds of behaviours [62].

It is well known that only a small part of the populations undergoing interventions to lose weight actually

Table 2 Study outcomes

\begin{tabular}{ll}
\hline Variables & Goal \\
\hline BMI & $5 \%$ z-score reduction \\
Body composition & $5 \%$ reduction of percent fat mass \\
Psychosocial & Improvements of 0.5 standard deviation \\
PA time & Increase moderate/vigorous PA ( $\geq 60$ min per day) \\
Sedentary behaviour & $\leq 90$ minutes per day \\
Caloric intake & $1000-1500$ Kcal daily intake \\
\hline
\end{tabular}

Note: PA - Physical Activity. succeed (and maintain) in the long term. Usually, as soon as the intervention ends, PA tends to decrease. As such, and as it is not possible to intervene directly in PA, where should we intervene? Research has shown how motivational processes may play a crucial role as mediators of behavioural change and maintenance [63]. Thøgersen-Ntoumani and Ntoumanis [64] showed the importance of encouraging self-determined motivation in order to improve the quality of the experience and the perpetuation of the behavioural change through exercise.

The sensation of choice or desire when facing a specific behaviour, places the individual in a privileged position in the motivation continuum [63], and can be manipulated through self-regulation. We believe this is a central question, given that SDT proposes that PA can be intrinsically motivated through increasing autonomy and skills development [63].

It is hoped that the results of this trial will contribute to increasing the knowledge on the different processes involved in the management of paediatric obesity (how, when, in which ways and why) and will enable to provide some answers that will for sure merit to be further explored.

\section{Competing interests}

The authors declare that they have no competing interests.

\section{Authors' contributions}

HF and ALP designed the study and wrote the first draft of the manuscript. ALP, SCM and LF designed the intervention and decided upon the data collection methods. ALP and AQ were responsible for the data analysis decisions and sample size calculations. HF is the principal investigator of the study, reviewed the draft and wrote the final version of the manuscript. All authors read and approved the final manuscript. 


\section{Acknowledgements}

This study protocol went through a peer-review process within the Portuguese Science Foundation grants system. The study was awarded a grant with the number PTDC/DES/113591/2009.

\section{Author details}

'Paediatric Obesity Clinic, Department of Paediatrics, Hospital de Santa Maria, Lisboa, Portugal. ${ }^{2}$ Faculdade de Educação Física e Desporto, Universidade Lusófona, Campo Grande 376, 1749-024 Lisboa, Portugal. ${ }^{3}$ CIPER - Faculdade de Motricidade Humana, Universidade de Lisboa, Portugal.

Received: 17 March 2014 Accepted: 28 March 2014

Published: 3 April 2014

\section{References}

1. Luttikhuis O, Baur L, Jansen H, Shrewsbury VA, O'Malley C, Stolk RP, Carolyn D, Summerbell C: Interventions for treating obesity in children (Review). Cochrane Database Syst Rev 2009, 1:CD001872

2. Sardinha LB, Santos R, Vale S, Silva AM, Ferreira JP, Raimundo AM, Moreira H, Baptista F, Mota J: Prevalence of overweight and obesity among Portuguese youth: a study in a representative sample of 10-18-year-old children and adolescents. Int J Pediatr Obes 2011, 6(2-2):e124-e128.

3. Kohn M, Rees JM, Brill S, Fonseca H, Jacobson M, Katzman DK, Loghmani ES, Neumark-Sztainer D, Schneider M: Preventing and treating adolescent obesity: a position paper of the Society for Adolescent Medicine. J Adolesc Health 2006, 38(6):784-787.

4. Waters E, De Silva-Sanigorski A, Hall BJ, Brown T, Campbell KJ, Gao Y, Armstrong R, Prosser L, Summerbell CD: Interventions for preventing obesity in children. Cochrane Database Syst Rev 2011, 12, CD001871.

5. Whitlock EP, O'Connor EA, Williams SB, Beil TL, Lutz KW: Effectiveness of Weight Management Interventions in Children: A Targeted Systematic Review for the USPSTF. Pediatrics 2010, 125(2):E396-E418.

6. Griffiths $L J$, Parsons TJ, Hill AJ: Self-esteem and quality of life in obese children and adolescents: A systematic review. Int J Pediatr Obes 2010, 5(4):282-304.

7. Stovitz SD, Pereira MA, Vazquez G, Lytle LA, Himes JH: The Interaction of Childhood Height and Childhood BMI in the Prediction of Young Adult BMI. Obesity 2008, 16(10):2336-2341

8. Singh AS, Mulder C, Twisk JWR, Van Mechelen W, Chinapaw MJM: Tracking of childhood overweight into adulthood: a systematic review of the literature. Obes Rev 2008, 9(5):474-488.

9. Farhat T, lannotti RJ, Simons-Morton BG: Overweight, obesity, youth, and health-risk behaviors. Am J Prev Med 2010, 38(3):258-267.

10. Dietz WH: Health Consequences of Obesity in Youth: Childhood Predictors of Adult Disease. Pediatrics 1998, 101:518-525.

11. Kolotkin RL, Meter K, Williams GR: Quality of life and obesity. Obes Rev 2001, 2:219-229.

12. Friedman KE, Reichmann SK, Costanzo PR, Musante GJ: Body image partially mediates the relationship between obesity and psychological distress. Obes Res 2002, 10(1):33-41.

13. Luppino FS, De Wit LM, Bouvy PF, Stijnen T, Cuijpers P, Penninx BWJH, Zitman FG: Overweight, Obesity, and Depression A Systematic Review and Meta-analysis of Longitudinal Studies. Arch Gen Psychiat 2010, 67(3):220-229.

14. Neumark-Sztainer D, Paxton SJ, Hannan PJ, Haines J, Story M: Does body satisfaction matter? Five-year longitudinal associations between body satisfaction and health behaviors in adolescent females and males. J Adolesc Health 2006, 39(2):244-251.

15. Strauss RS: Childhood obesity and self-esteem. Pediatrics 2000, 105(1):e15-e15.

16. Fonseca $\mathrm{H}$, Matos MG: Perception of overweight and obesity among Portuguese adolescents: an overview of associated factors. Eur J Public Health 2005, 15(3):323-328.

17. Anderssen SA, Cooper AR, Riddoch C, Sardinha LB, Harro M, Brage S, Andersen LB: Low cardiorespiratory fitness is a strong predictor for clustering of cardiovascular disease risk factors in children independent of country, age and sex. Eur J Cardiovasc Prev Rehabil 2007, 14(4):526-531.

18. Andersen L, Harro M, Sardinha L, Froberg K, Ekelund U, Brage S, Anderssen S: Physical activity and clustered cardiovascular risk in children: a crosssectional study (The European Youth Heart Study). Lancet 2006, 368(9532):299-304.
19. Ekelund U, Luan J, Sherar LB, Esliger DW, Griew P, Cooper A: Moderate to Vigorous Physical Activity and Sedentary Time and Cardiometabolic Risk Factors in Children and Adolescents. JAMA 2012, 307(7):704-712.

20. Ekelund U, Brage S, Froberg K, Harro M, Anderssen SA, Sardinha LB, Riddoch C, Andersen LB: TV viewing and physical activity are independently associated with metabolic risk in children: the European Youth Heart Study. PLoS Med 2006, 3(12):e488.

21. Smith KS, Christakis NA: Social networks and health. Annu Rev Sociol 2008, 34:405-429.

22. Porter JS, Bean MK, Gerke CK, Stern M: Psychosocial factors and perspectives on weight gain and barriers to weight loss among adolescents enrolled in obesity treatment. J Clin Psychol Med Settings 2010, 17(2):98-102.

23. Zeller MH, Reiter-Purtill J, Ramey C: Negative peer perceptions of obese children in the classroom environment. Obesity (Silver Spring) 2008, 16(4):755-762.

24. Jelalian E, Mehlenbeck R, Lloyd-Richardson EE, Birmaher V, Wing RR: 'Adventure therapy' combined with cognitive-behavioral treatment for overweight adolescents. Int J Obes (Lond) 2006, 30(1):31-39.

25. Smith AL: Perceptions of peer relationships and physical activity participation in early adolescence. J Sport Exerc Psychol 1999, 21:329-350.

26. Lewis BA, Marcus BH, Pate RR, Dunn AL: Psychosocial Mediators of Physical Activity Behavior Among Adults and Children. Am J Prev Med 2002, 23(2S):26-35

27. Teixeira PJ, Silva MN, Coutinho SR, Palmeira AL, Mata J, Vieira PN, Carraca EV, Santos TC, Sardinha LB: Mediators of weight loss and weight loss maintenance in middle-aged women. Obesity (Silver Spring) 2010, 18(4):725-735.

28. Lubans DR, Foster C, Biddle SJ: A review of mediators of behavior in interventions to promote physical activity among children and adolescents. Prev Med 2008, 47(5):463-470.

29. Rhodes RE, Pfaeffli LA: Mediators of physical activity behaviour change among adult non-clinical populations: a review update. Int J Behav Nutr Phys Act 2010, 7(1):37.

30. Wilfley DE, Kass AE, Kolko RP: Counseling and Behavior Change in Pediatric Obesity. Pediatr Clin N Am 2011, 58(6):1403-1424.

31. Markland D, Ryan RM, Tobin VJ, Rollnick S: Motivational interviewing and self-determination theory. J Soc Clin Psychol 2005, 24(6):811-831.

32. Fonseca H, Martins SS, Palmeira AL: Assessment and Treatment of Overweight Adolescents Based on Self-determination Theory: A multidisciplinary program. In Society of Adolescent Health and Medicine 2010. Toronto: Journal of Adolescent Health; 2010.

33. Dishion TJ, Dodge KA: Peer contagion in interventions for children and adolescents: Moving towards an understanding of the ecology and dynamics of change. J Abnorm Child Psychol 2005, 33(3):395-400.

34. Jelalian E, Sato A, Hart CN: The effect of group-based weight-control intervention on adolescent psychosocial outcomes: Perceived peer rejection, social anxiety, and self-concept. Child Health Care 2011, 40:197-211.

35. Kolb DA: Experiential Learning: Experience as the Source of Learning and Development. New Jersey: Prentice Hall; 1984.

36. Quinlan NP, Kolotkin RL, Fuemmeler BF, Costanzo PR: Psychosocial outcomes in a weight loss camp for overweight youth. Int I Pediatr Obes 2009, 4:134-142.

37. Ryan RM, Deci EL: Self-Determination Theory and the facilitation of intrinsic motivation, social development, and well-being. Am Psychol Assoc 2000, 55(1):68-78.

38. Palmeira AL, Markland DA, Silva MN, Branco TL, Martins SC, Minderico CS, Vieira PN, Barata JT, Serpa SO, Sardinha LB, Teixeira PJ: Reciprocal effects among changes in weight, body image, and other psychological factors during behavioral obesity treatment: a mediation analysis. Int J Behav Nutr Phys Act 2009, 6:9.

39. Spear BA, Barlow SE, Ervin C, Ludwig DS, Saelens BE, Schetzina KE, Taveras EM: Recommendations for treatment of child and adolescent overweight and obesity. Pediatrics 2007, 120:S254-S288.

40. Bravata DM, Smith-Spangler C, Sundaram V, Gienger AL, Lin N, Lewis R, Stave CD, Olkin I, Sirard JR: Using Pedometers to Increase Physical Activity and Improve Health: A Systematic Review. JAMA 2007, 298(19):2296-2304.

41. Salvy SJ, Roemmich JN, Bowker JC, Romero ND, Stadler PJ, Epstein LH: Effect of peers and friends on youth physical activity and motivation to be physically active. J Pediatr Psychol 2009, 34(2):217-225. 
42. Hardman CA, Horne PJ, Fergus-Lowe C: Effects of rewards, peer-modelling and pedometer targets on children's physical activity: a school-based intervention study. Psychol Health 2011, 26(1):3-21.

43. Davison KK, Schmalz DL: Youth at risk of physical inactivity may benefit more from activity-related support than youth not at risk. Int J Behav Nutr Phys Act 2006, 3:5

44. Jago R, Brockman R, Fox KR, Cartwright K, Page AS, Thompson JL: Friendship groups and physical activity: qualitative findings on how physical activity is initiated and maintained among 10-11 year old children. Int J Behav Nutr Phys Act 2009, 6(1):4.

45. Reiter-Purtill J, Ridel S, Jordan R, Zeller MH: The benefits of reciprocated friendships for treatment-seeking obese youth. J Pediatr Psychol 2010, 35(8):905-914.

46. O'Donovan G, Blazevich AJ, Boreham C, Cooper AR, Crank H, Ekelund U, Fox KR, Gately P, Giles-Corti B, Gill JMR, Hamer M, McDermott I, Murphy M, Mutrie N, Reilly JJ, Saxton JM, Stamatakis E: The ABC of Physical Activity for Health: A consensus statement from the British Association of Sport and Exercise Sciences. J Sports Sci 2010, 28(6):573-591.

47. Biddle SJ, Pearson N, Ross GM, Braithwaite R: Tracking of sedentary behaviours of young people: A systematic review. Prev Med 2010, 51(5):345-351

48. Tremblay MS, LeBlanc AG, Kho ME, Saunders TJ, Larouche R, Colley RC, Goldfield G, Gorber SC: Systematic review of sedentary behaviour and health indicators in school-aged children and youth. Int J Behav Nutr Phys Act 2011, 8:98.

49. Tremblay MS, Leblanc AG, Janssen I, Kho ME, Hicks A, Murumets K, Colley RC, Duggan M: Canadian sedentary behaviour guidelines for children and youth. Appl Physiol Nutr Metab 2011, 36(1):59-64-65-71.

50. Moreno LA, Ochoa MC, Warnberg J, Marti A, Martinez JA, Marcos A: Treatment of obesity in children and adolescents. How nutrition can work? Int J Pediatr Obes 2008, 3(1):72-77.

51. Epstein LH, Paluch RA, Beecher MD, Roemmich JN: Increasing Healthy Eating vs. Reducing High Energy-dense Foods to Treat Pediatric Obesity. Obesity (Silver Spring) 2008, 16(2):318-326.

52. Davis MM, Gance-Cleveland B, Hassink S, Johnson R, Paradis G, Resnicow K Recommendations for prevention of childhood obesity. Pediatrics 2007, 120:S229-S253.

53. Tudor-Locke C, Craig CL, Beets MW, Belton S, Cardon GM, Duncan S, Hatano Y, Lubans DR, Olds TS, Raustorp A, Rowe DA, Spence JC, Tanaka S, Blair SN: How many steps/day are enough? for children and adolescents. Int J Behav Nutr Phys Act 2011, 8(1):78

54. American College of Sports Medicine: ACSM's guidelines for exercise testing and prescription. 7th edn. Lippincott: Williams \& Wilkins; 2005.

55. Council on Sports Medicine and Fitness: Strength Training by Children and Adolescents. Pediatrics 2008, 121(4):835-840.

56. Robertson RJ, Goss FL, Andreacci JL, Dub JJ, Rutkowski JJ, Frazee KM, Aaron DJ, Metz KF, Kowallis RA, Snee BM: Validation of the Childrens OMNI-Resistance Exercise Scale of Perceived Exertion. Med Sci Sports Exerc 2005, 37(5):819-826.

57. Barlow SE: Expert committee recommendations regarding the prevention, assessment, and treatment of child and adolescent overweight and obesity: Summary report. Pediatrics 2007, 120:S164-S192.

58. Preacher KJ, Hayes AF: Asymptotic and resampling strategies for assessing and comparing indirect effects in multiple mediator models. Behav Res Methods 2008, 40(3):879-891.

59. Luzier JL, Berlin KS, Weeks JW: Behavioral Treatment of Pediatric Obesity: Review and Future Directions. Child Health Care 2010, 39(4):312-334

60. Fisher EB, Fitzgibbon ML, Glasgow RE, Haire-Joshu D, Hayman LL, Kaplan RM, Nanney MS, Ockene JK: Behavior matters. Am J Prev Med 2011, 40:e15-e30.

61. Steinbeck K, Baur L, Cowell C, Pietrobelli A: Clinical research in adolescents: challenges and opportunities using obesity as a model. Int J Obes 2009, 33(1):2-7.

62. Crosnoe R, McNeely C: Peer Relations, Adolescent Behavior, and Public Health Research and Practice. Fam Community Health 2008, 31(1S):S71-S80.
63. Ryan RM, Williams GC, Patrick H, Deci EL: Self-determination theory and physical activity: The dynamics of motivation in development and wellness. Hell J Psychol 2009, 6:107-124.

64. Thøgersen-Ntoumani C, Ntoumanis N: The role of self-determined motivation in the understanding of exercise-related behaviours, cognitions and physical self-evaluations. J Sports Sci 2006, 24(4):393-404.

doi:10.1186/1471-2431-14-89

Cite this article as: Fonseca et al:: Managing paediatric obesity: a multidisciplinary intervention including peers in the therapeutic process. BMC Pediatrics 2014 14:89.

\section{Submit your next manuscript to BioMed Central and take full advantage of:}

- Convenient online submission

- Thorough peer review

- No space constraints or color figure charges

- Immediate publication on acceptance

- Inclusion in PubMed, CAS, Scopus and Google Scholar

- Research which is freely available for redistribution

Submit your manuscript at www.biomedcentral.com/submit
C) BioMed Central 